Discussion Paper No. 02-28

\title{
The Economic and Environmental
} Implications of the US Repudiation of the Kyoto Protocol and the Subsequent Deals in Bonn and Marrakech

Andreas Löschel and ZhongXiang Zhang

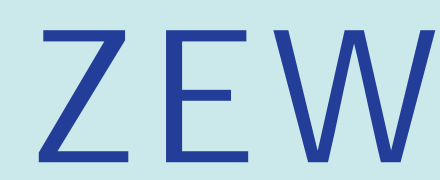

Zentrum für Europäische Wirtschaftsforschung $\mathrm{GmbH}$

Centre for European Economic Research 
Discussion Paper No. 02-28

\title{
The Economic and Environmental Implications of the US Repudiation of the Kyoto Protocol and the Subsequent Deals in Bonn and Marrakech
}

\author{
Andreas Löschel and ZhongXiang Zhang
}

Download this ZEW Discussion Paper from our ftp server:

ftp://ftp.zew.de/pub/zew-docs/dp/dp0228.pdf

Die Discussion Papers dienen einer möglichst schnellen Verbreitung von neueren Forschungsarbeiten des ZEW. Die Beiträge liegen in alleiniger Verantwortung der Autoren und stellen nicht notwendigerweise die Meinung des ZEW dar.

Discussion Papers are intended to make results of ZEW research promptly available to other economists in order to encourage discussion and suggestions for revisions. The authors are solely responsible for the contents which do not necessarily represent the opinion of the ZEW. 


\section{Nontechnical Summary}

Taking account of sinks credits as agreed in Bonn and Marrakech, this paper illustrates how market power could be exerted in the absence of the US ratification under Annex 1 trading and explores the potential implications of the non-competitive supply behavior for the international market of tradable permits, compliance costs for the remaining Annex 1 countries to meet their revised Kyoto targets, and the environmental effectiveness. Our results show that the US withdrawal from the Kyoto Protocol has had by far the greatest impact on the environmental effectiveness of the Protocol. This would lead to no real emission reduction in all remaining Annex 1 regions. As the biggest single buyer on the permit market, the absence of US ratification would significantly reduce the demand for permits. Consequently, the price of permits under Annex 1 trading would drop to zero. While all remaining Kyotoconstrained Annex 1 countries would enjoy meeting their revised Kyoto targets at zero costs, seller countries with excess supply of hot air would lose all their revenues under perfect Annex 1 trading.

Given the former Soviet Union (FSU) and the Eastern European countries (EEC) as the dominant suppliers of emissions permits on the international market, it seems likely that they would exert market power to maximize their revenues from permit sales. Depending on how market power is exerted, our results show that the overall compliance costs of all remaining Annex 1 regions in the case of FSU cooperating with EEC could reach as much as two times that in the case of only FSU acting as a monopoly. But no matter how market power is exerted, all Kyoto-constrained Annex 1 regions are better off with emissions trading in terms of their compliance costs than with no trading at all. Moreover, curtailing permit supply by market power will cut the amount of hot air being emitted into the atmosphere by more than half and at the same time, increase Annex 1 domestic abatement efforts. Thus, the overall environmental effectiveness is increased, although it is much less under the market power scenarios examined than in the case of the ratification of all Annex 1 regions including the US. 


\title{
The Economic and Environmental Implications of the US Repudiation of the Kyoto Protocol and the Subsequent Deals in Bonn and Marrakech
}

\author{
Andreas Löschel ${ }^{*}$ \\ Centre for European Economic Research (ZEW) and Mannheim University \\ ZhongXiang Zhang \\ Research Program, East-West Center
}

\begin{abstract}
Taking account of sinks credits as agreed in Bonn and Marrakech, this paper illustrates how market power could be exerted in the absence of the US ratification under Annex 1 trading and explores the potential implications of non-competitive supply behavior for the international market of tradable permits, compliance costs for the remaining Annex 1 countries to meet their revised Kyoto targets, and the environmental effectiveness. Our results show that the US withdrawal from the Kyoto Protocol has great impact on the economic costs and environmental effectiveness of the Protocol since it would lead to no real emission reduction in all remaining Annex 1 regions. Depending on how market power is exerted by the dominant permit suppliers, the former Soviet Union and the Eastern European countries, the overall compliance costs of all remaining Annex 1 regions differ significantly. Moreover, curtailing permit supply by market power increases substantially the overall environmental effectiveness by cutting the amount of hot air being emitted into the atmosphere by more than half, although to much less extent than in the case of the US compliance.
\end{abstract}

JEL classification: D43, Q43, Q48, Q25

Keywords: climate policy, emission trading, market power, Kyoto Protocol

We would like to thank Patrick Criqui for the provision of data on marginal abatement costs based on the POLES model. Christoph Böhringer provided useful comments and suggestions. Löschel gratefully acknowledges financial support from the European Commission under the project Climate Change Policy and Global Trade (CCGT) and Greenhouse Gases Emission Control Strategies (GECS). The views expressed here are those of the authors. The authors bear sole responsibility for any errors and omissions that may remain.

Centre for European Economic Research and Mannheim University, P.O. Box 1034 43, D-68034

Mannheim, Germany, Tel: +49-621-1235-186, Fax: +49-621-1235-226, Email: loeschel@ zew.de

*esearch Program, East-West Center, 1601 East-West Road, Honolulu, HI 96848-1601, USA, Tel: +1-808944 7265, Fax:+1-808-944 7298, Email: zhangz@eastwestcenter.org 


\section{Introduction}

The Kyoto Protocol to the United Nations Framework Convention on Climate Change (UNFCCC) imposes greenhouse gas emission limits for Annex 1 countries (i.e., the OECD countries and countries with economies in transition) as listed in Annex B of the Protocol. Together, Annex 1 countries must reduce their emissions of six greenhouse gases (GHG) by 5.2\% below 1990 levels over the commitment period 2008-2012. The Protocol also incorporates emissions trading, joint implementation and the clean development mechanism (CDM) to help Annex 1 countries meet their Kyoto targets at a lower overall cost, but it leaves all of the details concerning these flexibility mechanisms open for further negotiations. The Protocol will become effective once it has been ratified by at least 55 parties whose $\mathrm{CO}_{2}$ emissions represent at least 55\% of the total emissions from all Annex 1 parties in the year 1990.

The sixth Conference of the Parties to the UNFCCC (COP6) held in the Hague, November 2000, aimed to finalize the procedures and institutions needed to make the Kyoto Protocol fully operational. During the negotiations leading up to the conference, the long and contentious debates between the European Union on the one hand and the US and other members of the Umbrella Group ${ }^{1}$ on the other hand had centered on the two issues. The first contentious issue is to what extent Annex 1 countries could count their carbon absorbing forests and agricultural lands (the so-called sinks) against their emissions targets. The Americans were keen on the broadest and most generous definitions of sinks absorbing greenhouse gases in the atmosphere, while the Europeans wanted sharp curbs on the use of sinks. The clash between the US and the European Union (EU) over the extent of usage of the sinks to meet their emissions targets was blamed, in part, for the breakdown of the climate negotiations of the COP6. The second contentious issue is to what extent Annex 1 countries are allowed to use the flexibility mechanisms to meet their emissions targets. On the one hand, the US and other Umbrella Group members advocated unrestricted emissions trading. On the other hand, the EU put forward a proposal for quantitative ceilings on the use of flexibility mechanisms (European Union, 1999), insisting that domestic abatement actions should be a main means of meeting emissions reductions required of each Annex 1 country

\footnotetext{
${ }^{1}$ The Umbrella Group refers to the so-called JUSSCANNZ countries (Japan, the United States, Switzerland, Canada, Australia, Norway, New Zealand). It meets daily during the international climate change negotiations to exchange information and discuss substance/strategy on issues where there is common ground.
} 
(in other words, at least half of the emissions reductions required have to be undertaken domestically). This supplementary requirement caused the deepest division between the EU and the Umbrella Group countries and was regarded as one of the main causes for the collapse of the COP6.

Soon after coming into office, the President Bush decided that the US would withdraw from the Kyoto Protocol. Quick to accept that the US would not re-enter the negotiations, the EU led a sustained diplomatic effort to keep the Kyoto Protocol alive (Legge, 2001). While the Group of 77 (G77) and China ${ }^{2}$ moderated some of their demands, the EU softened its stance on the extent of usage of sinks and flexibility mechanisms to secure the reluctant support of other Umbrella Group members for the Protocol at the resumed COP6 held in Bonn, July 2001. After tough negotiations, the political compromises were eventually reached on a number of key implementation issues of the Kyoto Protocol. This political deal, called the Bonn Agreement, was translated into the detailed legal text, called the Marrakech Accords, at the seventh Conference of the Parties (COP7) to the UNFCCC held in Marrakech, November 2001, which was expected to be easy but turned out to be another difficult meeting. The Kyoto Protocol, as detailed in the Marrakech Accords, has been rendered fit for its ratification at the World Summit on Sustainable Development to be held Johannesburg, September 2002.

The Bonn Agreement allows for significant credits for carbon dioxide sinks. Specifically, the following activities related to land use, land use change and forestry (LULUCF) are allowed to be counted as sinks: forest management under Article 3.4, whose credits are capped to country-specific limits as given in Appendix $\mathrm{Z}$ and which total 83 million tons of carbon (MtC) per year; ${ }^{3}$ agricultural land management and revegetation activities under Article 3.4 on a net-net accounting basis without an explicit cap; afforestation and reforestation projects to be eligible under the CDM, whose contribution to a party's

\footnotetext{
${ }^{2}$ As has been the case at the international climate change negotiations, the developing countries express their consensus views as the Group of 77 and China's positions. Divergent or dissenting views are then expressed separately, representing either individual countries or smaller groups, such as the Alliance of Small Island States (AOSIS).

${ }^{3}$ At the COP7 to the UNFCCC, the Russian Federation demanded the renegotiation of the designated amount from forest management activities, and succeeded in increasing the amount from 17.63 megatons of carbon per year specified in Appendix Z under the Bonn Agreement to 33 megatons. This revision led to the new total of 98 $\mathrm{MtC}$, provided that an initial figure of $28 \mathrm{MtC}$ for the US was included.
} 
assigned amount is capped at $1 \%$ of five times the party's base year emissions (UNFCCC, 2001).

With the US withdrawal from the Kyoto Protocol, the EU dropped its previous insistence on a cap on the use of flexibility mechanisms. The final wording at the Bonn Agreement is now that "domestic action shall thus constitute a significant element of the effort" by each Annex 1 country. This is a very important and positive development because it will allow countries and businesses to reduce their emissions wherever it is cheapest to do so. Ironically, it is a development that the US had lobbied intensively for during previous rounds of international climate negotiations.

Earlier economic modeling studies focus on investigating economic efficiency and environmental effectiveness of meeting the original Kyoto reduction target of $5.2 \%$, with and/or without considering the imposition of restrictions on the use of emissions trading (e.g. Bernstein et al., 1999; Bollen et al., 1999; Criqui and Viguier, 2000; Criqui et al., 1999; Ellerman and Decaux, 1998; Ellerman, Jacoby and Decaux, 1998; Ellerman and Wing, 2000; Manne and Richels, 1999; Paltsev, 2000; Weyant, 1999; Zhang, 2000b, 2001). The results, among others, show that the US is expected to be the biggest single buyer on the international market of tradable permits, and that restrictions on the use of emissions trading to comply with the Kyoto emissions targets will result in substantial efficiency losses. The US withdrawal from the Kyoto Protocol breaks the balance of the buyers and sellers on the international permit market. The most recent studies focus on the implications of the US withdrawal from the Protocol. A large part of these studies assume perfectly competitive behavior, and show that the US non-ratification leads to a sharp drop in the price of permits on the international market so that the remaining Kyoto-constrained Annex 1 countries can meet their Kyoto targets at much lower costs (Hagem and Holtsman, 2001; Den Elzen and de Moor, 2001; Eyckmans et al., 2001). With the over-supply of permits, it seems likely that sellers would adapt their behaviors to the weaker demand for emissions permits to maximize their gains. Dominant sellers might defer portion of their excess emissions permits for use in subsequent periods and/or exploit their market power on the permits market (Manne and Richels, 2001; Buchner et al., 2001). Manne and Richels (2001) have examined the implications of allowing banking of permits, an intertemporal flexibility that allows countries to carry permits that are unused in one commitment period forward for use in the subsequent periods. They have found that the reduction in the compliance costs of the remaining Annex 1 
countries in the absence of the US ratification would be smaller than what have been suggested.

In the absence of the US ratification, market power on the supply side of the permit market seems likely to be a real issue. The ongoing international climate negotiations might give us some indications. With the US withdrawal from the Kyoto Protocol, Russian participation is essential for the Protocol to enter into force. ${ }^{4}$ As would be expected, the Russian Federation has exploited its increased bargaining power by further reducing its obligations. As observed at the recently completed COP7 where the EU and the G77 and China were determined to strike a deal that would ensure sufficient ratification for entry into force of the Protocol, the Russian Federation, both individually and collectively with other members of the Umbrella Group, used this leverage to compel the EU and G77/China to concede many of their demands (IISD, 2001). Despite the insistence of almost all parties that the Bonn Agreement was sacrosanct, the Russian Federation demanded the renegotiation of the designated amount from forest management activities, and succeeded in increasing the amount from $17.63 \mathrm{MtC}$ per year to $33 \mathrm{MtC}$.

Several studies have explored the implications of organizing a sellers' cartel (e.g., Böhringer and Löschel, 2001; Manne and Richels, 2001). But, in our view, there is an ample space for non-competitive supply behavior under Annex 1 emissions trading, and the realistic scenario of market power may lie somewhere in between the extreme scenarios of the perfect competition and the coordinated monopoly. Taking account of sinks credits as agreed in Bonn and Marrakech, this paper aims to illustrate how market power could be exerted in the absence of the US ratification under Annex 1 trading and to explore the potential implications of the non-competitive supply behavior for the international market of tradable permits, compliance costs for the remaining Annex 1 countries to meet their revised Kyoto targets, and the environmental effectiveness. Section 2 provides baseline emissions in 2010 for all Annex 1 regions, effective emissions reductions in all Kyoto-constrained Annex 1 regions and the size of hot air for those Kyoto-unconstrained Annex 1 regions. Section 3 discusses the analytical framework to study the effects of non-competitive supply behavior in the absence

\footnotetext{
${ }^{4}$ The US contributes $36.1 \%$ of the total Annex $1 \mathrm{CO}_{2}$ emissions in the year 1990 , whereas the Russian Federation is responsible for $17.4 \%$ (UNFCCC, 1997). The entry into force requires that countries representing at least $55 \%$ of the total $\mathrm{CO}_{2}$ emissions from Annex 1 countries in 1990 ratify the Protocol. Thus, the US and countries responsible for more than $8.9 \%$ of the total can block the Protocol from entering into force, implying that Russian ratification is required for the Protocol to enter into force.
} 
of the US ratification under Annex 1 emissions trading. Section 4 describes our partial equilibrium model based on the marginal abatement costs of seven Annex 1 regions, with the algebraic exposition of the model given in Appendix B. Section 5 presents the policy scenarios examined, whereas Section 6 discusses all simulation results. The paper ends with the main conclusions and further research.

\section{Baseline emissions, the mandated reductions and the size of hot air}

The magnitude and distribution of abatement costs of meeting the Kyoto emission constraints depend crucially on the business-as-usual (BAU) projections for emissions. This study takes the year 2010 as representative of the first commitment period 2008-2012. Like other economic modeling studies on compliance costs (see Weyant, 1999), the study focuses only on $\mathrm{CO}_{2}$, partly because $\mathrm{CO}_{2}$ is the most important of the six greenhouse gases considered under the Kyoto Protocol, and partly because of lack of appropriate abatement cost data for non- $\mathrm{CO}_{2}$ greenhouse gases. ${ }^{5}$ Moreover, because it is a daunting task to estimate the marginal abatement cost for each Annex 1 country, we do so at a regional level. We aggregate Annex 1 countries into seven regions; Australia and New Zealand (AUN), Canada (CAN), Europe Union (EUR), Japan (JPN), the US (USA), Eastern Europe (EEC) and the former Soviet Union (FSU) (see Appendix A for the corresponding Annex 1 countries covered in each region). The first five Kyoto-constrained regions belong to the Organisation for Economic Co-operation and Development (OECD). Historical $\mathrm{CO}_{2}$ emissions for each Annex 1 country in the base year 1990 as well as its projected $\mathrm{CO}_{2}$ emissions in 2010 are derived from the US Department of Energy (DOE, 2001). They are aggregated into the above seven Annex 1 regions, as given in Table 1. The table also contains the nominal percentage reductions with respect to (wrt) 1990 emissions levels and the effective percentage reductions with respect to baseline emissions in 2010 for both the original Kyoto emissions targets and the revised targets under the Bonn Agreement and the Marrakech Accords. The latter are based on the preliminary estimates by the European Commission factoring into the amount of sinks credits as agreed in Bonn and Marrakech (Nemry, 2001). As a result of allowing countries to count

\footnotetext{
${ }^{5}$ Inclusion of non- $\mathrm{CO}_{2}$ greenhouse gases will lower absolute compliance costs, given that other greenhouse gases but $\mathrm{CO}_{2}$ can be cut at lower costs. But, as Manne and Richels (2001) point out, the focus on $\mathrm{CO}_{2}$ would not alter the general insights from this kind of analysis.
} 
the amount of sinks credits, the average reduction target for the Annex 1 countries as a whole is reduced to $1.9 \%$, in comparison to the original reduction target of 5.2\% (see Table 1).

It can be seen that $\mathrm{CO}_{2}$ emissions in all the OECD countries in 2010 are expected to continue to rise under the BAU scenario. Consequently, their effective percentage reductions from their projected baseline emissions are much higher than their nominal percentage reductions. Even if the sinks credits are factored into, meeting the Kyoto targets still requires a drastic reduction in emissions for AUN, CAN, EUR, JPN and USA.

The situation in the former Soviet Union and Eastern Europe is quite different. The economic transition led to a large decline in emissions as economies contracted and energy markets were deregulated since the collapse of the Soviet Union. By 1996, greenhouse gas emissions in these countries had declined $20-46 \%$ below their base year levels (Zhang, 2001). Although economies are projected to begin recovering during the period under review, emissions in most countries with economies in transition in 2010 are expected to remain below their base year levels. In other words, these countries are allocated assigned amounts under the Kyoto Protocol that exceed their anticipated emissions requirements even in the absence of any limitation. If emissions trading were allowed, these countries would be able to trade these excess emissions to other countries, thus creating the hot air that would otherwise have not occurred in the absence of emissions trading (Zhang, 1998, 2000a). Because the transfer of the hot air does not represent any real emissions reductions by the selling countries, allowing the acquisition of the surplus from the selling countries to meet the buying countries' commitments makes the total emissions even higher than what would be in the absence of emissions trading, although not above the aggregate Kyoto targets (Zhang, 2000b).

The hot air problem is particularly acute in Russia and the Ukraine. But the exact amount of hot air is by its nature uncertain. This depends particularly on expectations for economic recovery and developments in the energy sector in Russia and Ukraine. Optimistic expectations for economic recovery increases benchmark carbon emissions in 2010, shifting aggregate demand curves outwards and aggregate supply curves inwards on the international permit market, leading to a smaller amount of hot air than those projected based on less optimistic expectations for economic recovery. Most economic modeling studies project a size of hot air in the range from $111 \mathrm{MtC}$ to $374 \mathrm{MtC}$ in 2010 (Paltsev, 2000; Zhang, 2000b). Our projections of hot air for Russia and the Ukraine are based on the most recent projections for baseline carbon emission by the US Department of Energy (DOE, 2001). As indicated in 
Table 1, comparing the official DOE baseline projections for 2010 with the revised Kyoto emissions targets suggests a size of hot air of $296 \mathrm{MtC}$ for FSU and $56 \mathrm{MtC}$ for EEC. The withdrawal of the US as the world largest potential buyer of emissions permits leads to an excess supply of hot air of $54 \mathrm{MtC}$. If emissions permits were fully tradable among all remaining Annex 1 countries, a competitive market of permits would drive down the international price of permits to zero so that no real emissions reductions in Annex 1 countries at all would occur with respect to their BAU emissions.

Table 1 Quantitative implications of the Marrakech Accords

\begin{tabular}{|c|c|c|c|c|c|c|c|c|}
\hline \multirow[t]{2}{*}{ Region $^{\mathrm{a}}$} & \multicolumn{2}{|c|}{$\begin{array}{l}\text { Baseline } \\
\text { emissions } \\
(\mathrm{MtC})^{\mathrm{b}}\end{array}$} & \multicolumn{2}{|c|}{$\begin{array}{c}\text { Nominal } \\
\text { reduction } \\
(\% \text { wrt 1990) }\end{array}$} & \multicolumn{2}{|c|}{$\begin{array}{c}\text { Effective } \\
\text { reduction } \\
(\% \text { wrt 2010) }\end{array}$} & \multicolumn{2}{|c|}{$\begin{array}{c}\text { Absolute } \\
\text { cutback } \\
(\mathrm{MtC} \text { wrt 2010) }\end{array}$} \\
\hline & 1990 & 2010 & w/o sink & $\mathrm{w} / \mathrm{t}$ sinks & w/o sink & $\mathrm{w} / \mathrm{t} \operatorname{sinks}$ & w/o sink & $\mathrm{w} / \mathrm{t} \operatorname{sinks}$ \\
\hline AUN & 88 & 130 & -6.8 & -9.4 & 27.6 & 25.9 & 36 & 34 \\
\hline CAN & 126 & 165 & 6.0 & -5.2 & 28.2 & 19.7 & 47 & 32 \\
\hline EUR & 930 & 1040 & 7.8 & 6.2 & 17.5 & 16.1 & 182 & 168 \\
\hline JPN & 269 & 330 & 6.0 & 1.1 & 23.4 & 19.4 & 77 & 64 \\
\hline EEC & 279 & 209 & 7.1 & 4.9 & -24.0 & -26.9 & -50 & -56 \\
\hline FSU & 853 & 593 & 0 & -4.2 & -43.8 & -49.8 & -260 & -296 \\
\hline Total w/o US & 2545 & 2467 & 4.3 & 0.9 & 1.3 & -2.2 & 32 & -54 \\
\hline USA & 1345 & 1809 & 7.0 & 3.7 & 30.9 & 28.4 & 558 & 514 \\
\hline Total w/t US & 3890 & 4276 & 5.2 & 1.9 & 13.8 & 10.8 & 590 & 460 \\
\hline
\end{tabular}

${ }^{\text {a }}$ AUN - Australia and New Zealand; CAN - Canada; EUR - OECD Europe (including EFTA); JPN - Japan; EEC - Central and Eastern European countries; FSU - Former Soviet Union.

${ }^{\mathrm{b}}$ Baseline emissions in 2010 based on DOE (2001) reference case.

${ }^{c}$ Estimates based on UNFCCC and FAO data (Nemry, 2001).

d Annex 1 total without the US ratification.

${ }^{\mathrm{e}}$ Annex 1 total with the US ratification. 


\section{The effects of market power in international emissions trading}

A number of theoretical and empirical studies have examined the issue of market power on tradable quota markets (e.g., Hahn, 1984; Misolek and Elder, 1989; Malueg, 1990; Westkog, 1996; Sartzetakis, 1997; Burniaux, 1998; Ellerman and Decaux, 1998; Ellerman and Wing, 2000; Godby, 2000). They show that either dominant buyers (monopsony/oligopsony) or sellers (monopoly/oligopoly) may be able to exert market power on the permit market or use its market power on the permit market to gain power in the product market. In the following discussion, market power refers only to the capacity to influence the market price of traded permits ("cost minimizing manipulation").

The impact of market power on the price of permits depends on who resides in such a power. In the case of a monopsony, market power under emissions trading results in reduced demand, whereas in the case of a monopoly market power under emissions trading results in reduced supply. A monopsonist may thereby force the permit price below, a monopolist above the competitive level (Misolek and Elder, 1989). Thus, the extent of competition on a tradable permit market affects the efficiency of international emissions trading and the degree to which potential cost savings are realized. Permit price manipulations result in additional economic costs to achieve the same level of abatement as under a perfect competition and increase the costs of compliance. Whether market power is a real issue in an international greenhouse gas emissions trading depends on how such a trading scheme will take place. Article 17 of the Kyoto Protocol creates an intergovernmental emissions trading market next to inter-source trading. ${ }^{6}$ In case of inter-source trading in which sub-national entities (e.g., firms) are authorized to trade on the international emissions permit market, the scope of market power seems rather limited. ${ }^{7}$ Emissions trading modeled in many economic studies (Weyant, 1999) operates as if governments retain the sole right to trade. As such, emissions

\footnotetext{
${ }^{6}$ See Zhang (1998, 2000a) for a detailed discussion on inter-governmental emissions trading and inter-source trading.

${ }^{7}$ Incorporating sub-national entities into an international emissions trading scheme would potentially increase the total amount of transactions in the international scheme. Increasing the number of trades would help to improve market liquidity and reduce the potential for abuse of market power. Hargrave (1998) shows that if an upstream trading system, which targets fossil fuel producers and importers as regulated entities, were implemented in the US, the total number of allowance holders would be restricted to about 1900. Even with such a relatively small number of regulated sources, market power would not be an issue. In the above upstream system for the US, the largest firm has only a 5.6 percent market allowance share. Firms, each having less than one percent share, would hold the lion's share of allowances (Cramton and Kerr, 1998).
} 
trading takes place on a government-to-government basis. Since the majority of inexpensive emissions permits are concentrated in the Eastern European and former Soviet Union countries, these countries may be able to exert market power and extract sizeable economic rents under this trading scheme. The scope for non-competitive supply behavior on Annex 1 permit market is significantly amplified by the US withdrawal from the Kyoto Protocol and the subsequent deals struck in Bonn and Marrakech. Factoring into the amount of sinks credits in the deals, the amount of EEC and FSU hot air available at no costs exceeds the total amount of emissions reductions required of all remaining Kyoto-constrained Annex 1 countries. The international permit price under Annex 1 trading falls to zero with perfectly competitive supply behavior of EEC and FSU. In this case, emission sales do not create any revenue for the two permit suppliers. Therefore, it seems plausible to assume that EEC and FSU restrict permit supply as a result of monopolistic behavior in order to drive up the international carbon price. Manne and Richels (1999) refer to this case as a sellers' market. On the demand side, competitive behavior seems to be the appropriate assumption. The reason is that either firms of the OECD countries are allowed to engage in emissions trading directly as proposed in the recent EU-wide emissions trading scheme, ${ }^{8}$ or coordination of several individual OECD countries to organize a buyers' cartel seems rather difficult in case of intergovernmental emissions trading.

Given the revised emissions targets at the COP7, the effects of supply side restrictions are illustrated in Figure 1. The amount of hot air $(H)$ is greater than the total abatement requirements of non-US Annex 1 countries $\left(Q_{u}\right)$. Consequently, market price under perfect competition is zero $\left(P_{u}=0\right)$ and the quantity of permits traded equals the total abatement requirement $\left(Q_{u}\right)$. There is no domestic abatement of Kyoto-constrained Annex 1 countries. Emissions of permit importers equal the BAU emission levels $(\bar{e})$. Total revenues for permit exporting countries equal zero. With supply side restrictions, the supply of permits is reduced from $S_{u}$ to $S_{r}$. This drives up the market price of permits from $P_{u}$ to $P_{r}$. The total volume of permits traded is reduced from $Q_{u}$ to $Q_{r}$. The exercise of monopoly power entails a redistribution of the gains from emissions trading from buyers to sellers and a loss of efficiency. Permit exporters receive the rectangle IJKO, which represents the total income

\footnotetext{
${ }^{8}$ On 23 October 2001, the Commission of European Communities (2001) adopted a proposal for implementing EU-wide emissions trading. Such a scheme involves company trading, should start in 2005, and in the first phase only covers $\mathrm{CO}_{2}$ emissions from large industrial and energy activities. These activities of about 4000-5000 major polluters are estimated to account for about $46 \%$ of the EU's total $\mathrm{CO}_{2}$ emissions in 2010.
} 
from permit sales. They benefit from further supply restrictions as long as the gains from higher prices are greater than the loss of revenues from a lower level of permits sold. Due to the higher price of permits, importing countries increase domestic abatement $(a)$, thus reducing emissions from $\mathrm{BAU}$ emissions $\bar{e}$ to $e$. The remaining abatement requirements up to the revised Kyoto target $(k)$ is met through permit import $(q)$. The costs of compliance for a permit importer increase to $L M N W$, of which $L M V W$ is the income transfer to permit exporters and $M N V$ is the increased resource cost (deadweight loss). The economic efficiency of emissions trading is reduced under market power since marginal abatement costs $\left(C^{\prime}\right)$ are not equalized across regions. The loss in efficiency relative to the competitive case depends on the amount of permits initially allocated to the regions (Hahn, 1984). With noncompetitive supply behavior, some part of hot air is suppressed $\left(Q_{u}-Q_{r}\right)$ and thus the environmental effectiveness is increased.
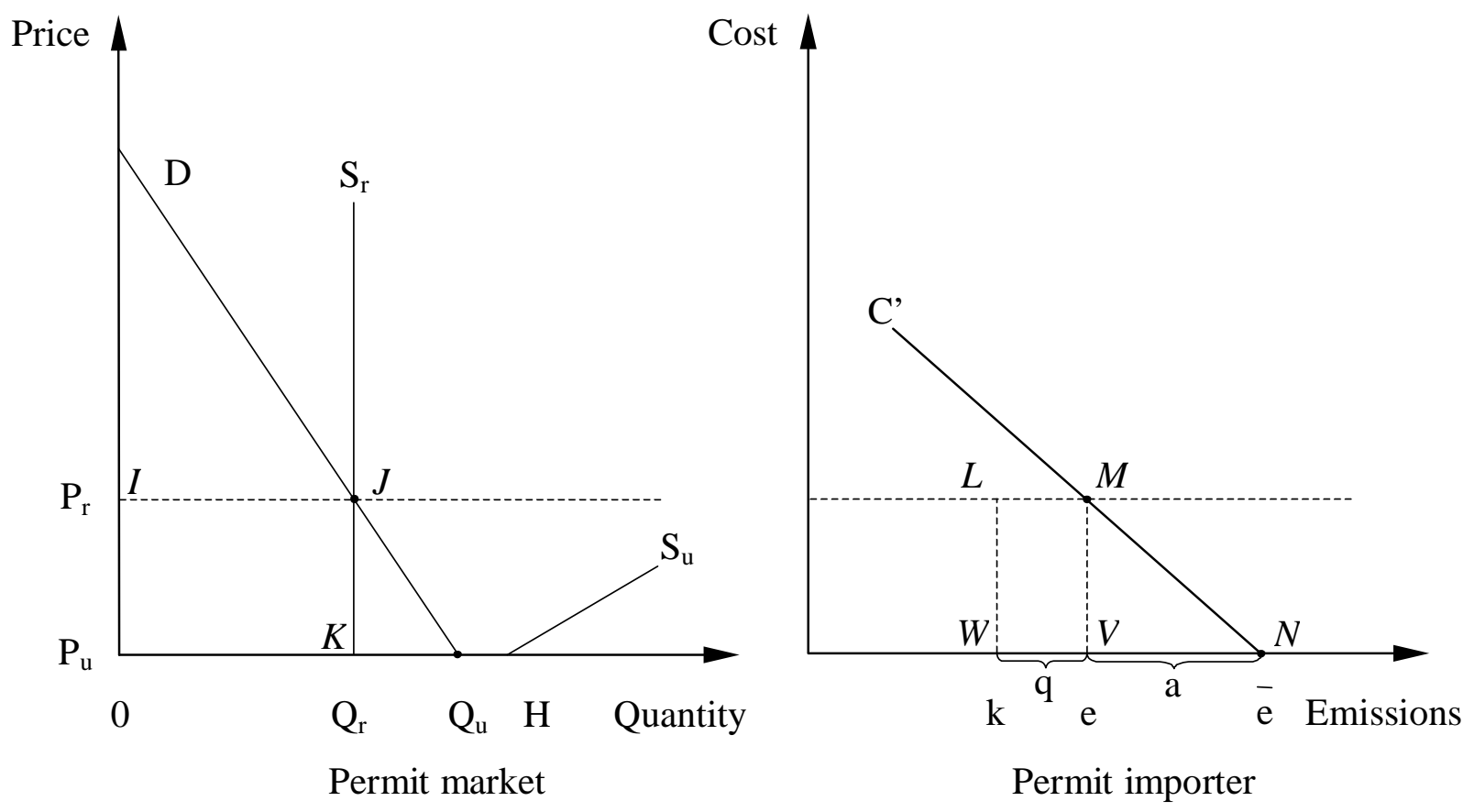

Figure 1 Effects of supply side restrictions 


\section{Partial equilibrium model of non-competitive supply behavior}

We assess the effects of non-competitive supply behavior in a partial equilibrium setup using marginal abatement cost (MAC) curves for different Annex 1 regions in the year 2010 (see Appendix B for the algebraic exposition of the model). These curves represent the marginal cost of reducing carbon emissions by different amounts within an economy. Marginal costs of abatement differ considerably across countries due to differences in the carbon intensity, initial energy price levels and the substitution possibilities in the respective economy.

The MAC curves used here are generated by the world energy system model POLES (Criqui et al., 1996), which embodies a detailed bottom-up description of regional energy markets and world-wide energy trade. To get the marginal abatement cost curves, we run the model under progressively stringent carbon constraints for the year 2010. The shadow price of carbon is plotted against the abatement levels and we fit a constant elasticity function to the model results using a least-squares procedure. The coefficients of the marginal abatement cost curve approximations of the form MAC $=\alpha \cdot(\text { ABATEMENT })^{\beta}$ are given in Table $2 .^{9}$ The MAC analysis is a partial equilibrium approach since it does not consider all the spillover effects of carbon abatement policies and monopolistic pricing on other markets. For instance, abating countries do not take into account the effects of carbon reduction efforts on energy prices and thereby its terms of trade. However, it provides a convenient way to analyze the effects of different assumptions on non-competitive supply side behavior.

Table 2 Coefficients of MAC curve approximations MAC $=\alpha \cdot\left(\right.$ ABATEMENT) ${ }^{\beta}$

\begin{tabular}{cccccccc}
\hline Coefficients & AUN & CAN & EEC & EUR & FSU & JPN & USA \\
\hline$\alpha$ & 0.675 & 1.567 & 0.316 & 0.114 & 0.046 & 0.718 & 0.020 \\
$\beta$ & 1.442 & 1.379 & 1.388 & 1.369 & 1.482 & 1.338 & 1.427 \\
\hline
\end{tabular}

\footnotetext{
${ }^{9}$ Ellerman and Decaux (1998) show that MAC curves generated in this way are robust with regard to emissions trading policies (i.e. different levels of abatement among regions and the scope of emissions trading). Zhang (2000b, 2001) has used the MACs of 12 regions to investigate the implications of quantitative limits on trading for Annex 1 countries and non-Annex 1 countries as well as for the market price of permits.
} 
The marginal abatement cost curves for the Kyoto-constrained Annex 1 regions, namely Australia and New Zealand (AUN), Canada (CAN), OECD Europe (EUR), and Japan (JPN) as well as the US (USA), are displayed in Figure 2. From these MAC curves we can derive the aggregate demand curve for permits of the Kyoto-constrained, i.e. importing Annex 1 regions, with and without the US participation. An Annex 1 region demands permits as long as the market price of permits is lower than its autarkic marginal abatement costs. Conversely, it supplies permits as long as the market price is above its autarkic marginal costs of abatement. The demand curve is then obtained by simply adding up the potentially demanded and supplied quantities of all Kyoto-constrained Annex 1 regions at each market price. If the market price is equal to zero, which is the result under the assumption of perfect competition, all constrained Annex 1 regions demand their Kyoto emission reduction requirements, which sum up to $298 \mathrm{MtC}$ and $812 \mathrm{MtC}$ without and with the US participation, respectively. As the price increases, the aggregate demand diminishes. When the market price reaches 108 $\mathrm{US} \$ / \mathrm{tC}$, the autarkic marginal abatement cost of $\mathrm{AUN}$, this region switches from demanding to supplying permits. The same happens at a price of $127 \mathrm{US} \$ / \mathrm{tC}$ for EUR. At a price of 140 US\$/tC, the amount of permits supplied by AUN ( $7 \mathrm{MtC}$ ) and EUR (12 MtC) just equals the demand by CAN (6 MtC) and JPN (13 MtC) resulting in an aggregate permit demand (without the US) of zero.

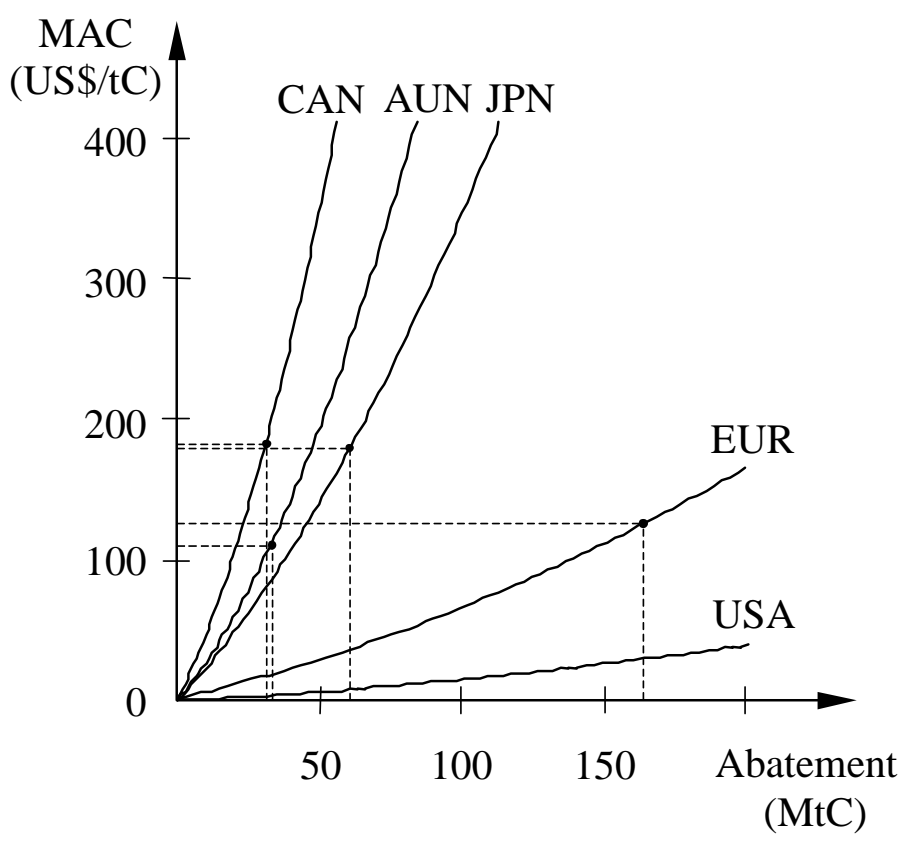

Figure 2 Marginal abatement cost curves for Kyoto-constrained Annex 1 regions 


\section{Formulation of policy scenarios}

Using the marginal abatement cost curves of seven Annex 1 regions and the market demand curve for permits (the curve D without the US participation and $\mathrm{D}_{\text {US }}$ with the US participation in Figure 5), we will examine the following policy scenarios:

NOTRADE Each Annex 1 country must individually meet its Kyoto targets without any trading of permits across national borders. This is equivalent to a case in which each Annex 1 country applies domestic carbon tax that is high enough to meet its individual Kyoto commitment. With the EU backing off earlier demand for placing quantitative limits on trading, this scenario seems unlikely. But it provides a useful reference point for examining the potential efficiency gains of emissions trading and the corresponding environmental effectiveness.

TRADE All Annex 1 countries including FSU and EEC are allowed to trade emissions permits with each other. Under the assumption of perfectly competitive supply and demand behavior, all regions behave as price takers. There is no market power exercised on the international permit market. We consider two variants: one with the US (TRADE w/t US), and one without the US (TRADE w/o US). This distinction aims to examine how the US withdrawal from the Protocol affects compliance costs of other Annex 1 countries and environmental effectiveness vis-à-vis full Annex 1 trading.

As discussed in Section 3, the assumption of perfectly competitive supply behavior seems unrealistic. Given FSU and EEC as the dominant suppliers of emissions permits on the international market, it is not in their interest to sell excess permits at zero price. Instead, they may exert market power to maximize their revenues from selling permits. To illustrate how market power could be exerted under Annex 1 trading and to explore the effects of the noncompetitive supply behavior, we set up the following three scenarios:

CARTEL FSU and EEC coordinate their permit supply to maximize joint profits forming a sellers' cartel. This is in effect a monopoly, and the members of the cartel share the monopolistic profits. All other regions behave as price takers, i.e. they minimize their abatement costs given the permit price set by the two regions.

NASH FSU and EEC behave non-cooperatively and do not coordinate their permit supply. Instead, they act independently of each other, with each region 
attempting to maximize its profit by choosing its own permit supply. This structure on the permits market is analyzed for a duopoly competing in quantities using the Nash equilibrium concept.

MONOP Only FSU acts as a monopoly. EEC is treated as a competitive fringe (price taker) following the price leadership of the dominant supplier FSU.

\section{Simulation results}

\section{A. NOTRADE}

Without emissions trading, each Annex 1 country must meet its Kyoto abatement commitment as indicated in Table 1 by solely undertaking domestic abatement actions. The autarkic marginal costs of abatement are $108 \mathrm{US} \$ / \mathrm{tC}$ for $\mathrm{AUN}, 127 \mathrm{US} \$ / \mathrm{tC}$ for $\mathrm{EUR}, 190$ US\$/tC for CAN and $187 \mathrm{US} \$ / \mathrm{tC}$ for JPN. The autarkic marginal abatement cost for USA in the case of its compliance with the Kyoto Protocol is 148 US\$/tC. EEC and FSU do not face any binding abatement requirements and thus their autarkic marginal costs of abatement are zero. The total costs of abatement without trade, which represent the areas under the marginal abatement cost curves, are US\$1.5 bn for AUN, US\$ 2.6 bn for CAN, US\$ 9.0 bn for EUR, US\$ 5.1 bn for JPN and US\$ 31.3 bn for USA. In terms of relative compliance cost measured as a percentage of the official DOE (2001) projection for GDP in 2010, EUR bears by far the smallest compliance burden (0.08\% GDP loss). With $0.27 \%$ GDP loss, CAN is hit hardest. With the loss of US\$31.3 bn and $0.24 \%$ GDP, the costs for USA are among the highest in both absolute and relative terms. The total compliance costs of Annex 1 countries including the US amount to US\$ 49.5 bn $(0.15 \%$ GDP loss). With respect to the environmental effectiveness, the absence of the US ratification leads to a real emission reduction of $298 \mathrm{MtC}$ (7.0\% effective reduction from the total Annex 1 baseline emissions in 2010), whereas an effective emission reduction with the US ratification amounts to $812 \mathrm{MtC}$, or $19.0 \%$ below the total Annex 1 baseline emissions in 2010 .

In what follows, we will discuss the effects of emissions trading under the different policy scenarios considered subsequently. Unless otherwise specified, all the numbers cited in this section are given in Table 3 . 


\section{B. TRADE - The effects of Annex 1 emissions trading under perfect competition}

\section{TRADE w/o US}

In the absence of the US ratification, the price of permits under perfect Annex 1 trading equals zero - assuming no transaction costs - since the amount of hot air exceeds the total amount of the revised emissions reductions required of all remaining Kyoto-constrained Annex 1 regions. None of the remaining Annex 1 countries with effective abatement requirements abate domestically at all, and their total compliance costs for meeting the revised Kyoto emissions targets are zero. Their total gains from emissions trading, namely the reductions in the total compliance costs relative to the no emissions trading case, amount to US\$ 18.2 bn $(0.09 \%$ of GDP). But the magnitude of the gain of each region depends on the relative differential between its autarkic marginal cost and the market price of permits. Ceteris paribus, regions whose autarkic marginal costs differ significantly from the trading equilibrium price (i.e. EUR, JPN) trade more and thus benefit more than those regions with autarkic marginal abatement costs closer to the permit price (of zero), i.e. AUN. ${ }^{10}$ The same reasoning applies to permit exporters. The farther away the permit price is from the autarkic marginal abatement costs, the more revenues they are able to receive from selling excess permits. With perfect competition, the autarkic marginal abatement costs of permit exporters FSU and EEC equal the permit price. Consequently, these two regions do not benefit at all from emissions trading.

It should be pointed out that while all remaining Kyoto-constrained Annex 1 regions benefit from excess supply of hot air from FSU and EEC in the absence of the US ratification, the environmental effectiveness under unconstrained Annex 1 trading drops to zero in comparison with a reduction of $19.0 \%$ from the total Annex 1 baseline emissions in 2010 in the case where all Annex 1 countries, including the US, ratify the Kyoto Protocol and trading across Annex 1 countries is not allowed. In other words, under unrestricted emissions trading, Kyoto comes at no costs because the world economy and its emissions develop as in the business-as-usual case. The total Annex 1 carbon emissions in 2010 remain unchanged at about 2.5 gigatons of carbon $(\mathrm{GtC})$.

\footnotetext{
${ }^{10}$ Under this scenario, all regions just trade their emission reduction requirements. Therefore, the trade volume is larger for AUN than for CAN.
} 


\section{TRADE w/t US}

When all Annex 1 countries, including the US, are allowed to trade emissions permits, the marginal cost of domestic abatement for each Annex 1 region equalizes. The resulting market price of permits is equal to US\$ 41 per ton of carbon. The total market size (i.e. total volume of traded permits) is estimated at $482 \mathrm{MtC}$. All Kyoto-constrained Annex 1 regions are permit importers: AUN demands 16.6 MtC, CAN 21.8 MtC, EUR 94.7 MtC, JPN 43.5 $\mathrm{MtC}$ and USA 305.6 MtC. By contrast, all Kyoto-unconstrained Annex 1 regions are permit exporters: EEC supplies 89.4 MtC and FSU 392.8 MtC. Unlike the case of US nonratification, both regions sell not just hot air, but are also involved in domestic abatement actions: EEC abates 33.1 MtC and FSU 97.3 MtC domestically. The total Annex 1 compliance costs are reduced from US\$ 49.5 bn in the case of no emissions trading (NOTRADE) to US\$ 7.7 bn with trading. At the same time, trading across all Annex 1 countries leads to a real emission reduction of $460 \mathrm{MtC}$, or $10.8 \%$ below the total Annex 1 baseline emissions in 2010 .

\section{CARTEL - EEC and FSU coordinate permit supply}

Our first specification of non-competitive behavior looks at the cooperative solution. The strategies of EEC and FSU are coordinated so as to attain the best result for the group. In so doing, they form a cartel and act as a monopoly in order to maximize its profit from permit sales, which is then divided among themselves by some prearranged rule. The cartel faces the downward sloping residual demand curve (the curve D in Figure 5). The aggregate cartel restricts the supply of permits until the marginal revenue from permit sales is equal to marginal abatement cost, i.e. equal to zero for hot air supply. At this point, the higher price just compensates for the decrease in the quantity exported, and the demand elasticity is equal to unity. The more inelastic the demand curve facing the cartel, the higher the price the cartel can set and the greater its profit. Monopolization has the expected effects: the cartel supplies only $126 \mathrm{MtC}$ permits to the market. The market price with monopolistic supply is raised to $66 \mathrm{US} \$ / \mathrm{tC}$ in comparison with zero in the absence of the US ratification under perfect Annex 1 trading. This is the maximum price that can be attained with supply side restrictions. Consequently, gains from trading are reduced from US\$ 18.2 bn under perfect competition to US\$ 13.4 bn under a supply cartel (see Table 3). This is mainly because Kyoto-constrained 
Annex 1 regions suffer from a substantial loss (US\$ 13.1 bn) in comparison with the case of perfectly competitive trade.

The loss of Kyoto-constrained Annex 1 regions is split up into incurred cost of domestic abatement and transfers made to permit suppliers. The increased resource costs due to domestic abatement add up to 4.8 bn US\$: US\$ 0.6 bn for AUN (24 MtC), US\$ 0.4 bn for CAN (15 MtC), US\$ 2.9 bn for EUR (104 MtC) and US\$ 0.8 bn for JPN (29 MtC). The total expenditures for permit purchases amount to US\$ 8.3 bn: US\$ 0.6 bn for AUN (10 MtC), US\$ 1.1 bn for CAN (17 MtC), US\$ 4.2 bn for EUR (64 MtC), and US\$ 2.3 bn for JPN (35 $\mathrm{MtC}$ ). Despite the efficiency losses, all Kyoto-constrained Annex 1 regions are still better off with emissions trading under a supply cartel than under no trading at all. In comparison with the case of no emissions trading, they gain US\$ 5.2 bn: AUN gains US\$ 0.2 bn, CAN US\$ 1.0 bn, EUR US\$ 1.9 bn and JPN US\$ 2.0 bn.

Expenditures for permit purchases are transferred to the cartel suppliers EEC and FSU. Thus, the total (maximum) gain of the cartel equals the total expenditures for permit purchases, which amount to US\$ 8.3 bn. In comparison with zero profits from permit sales under a perfect competition, such dramatic increases in profits enhance the incentive for the two regions to coordinate their permit sales. The cartel must decide how the monopoly profit of the cartel is to be divided among EEC and FSU. The range of possible cooperative solutions can be narrowed down. The payoffs to the two participants cannot add up to more than US\$ $8.3 \mathrm{bn}$. Since each region can choose to go alone, neither will accept a payoff less than under the NASH scenario derived later (US\$ 3.1 bn for EEC and US\$ 4.4 bn for FSU). Thus, all points on the solid line $\mathrm{AB}$ in Figure 3 are possible solutions to the bargaining problem (solution set). There have been several cooperative game solution concepts proposed. We consider only the egalitarian solution here. The symmetric or even split point is given by E (US\$ 0.4 bn for EEC, US\$ 0.4 bn for FSU). The profit of EEC amounts then to US\$ 3.5 bn, that of FSU to 4.8 bn US\$. It is undecided, however, how much is supplied to the market by each region. If, for example, EEC supplies its $56 \mathrm{MtC}$ of hot air, it receives 3.7 bn US\$ from permit sales and must pay US\$ 0.2 bn as a side payment to FSU. Given the larger bargaining power by FSU, the cooperative solution may lay more towards point A. 


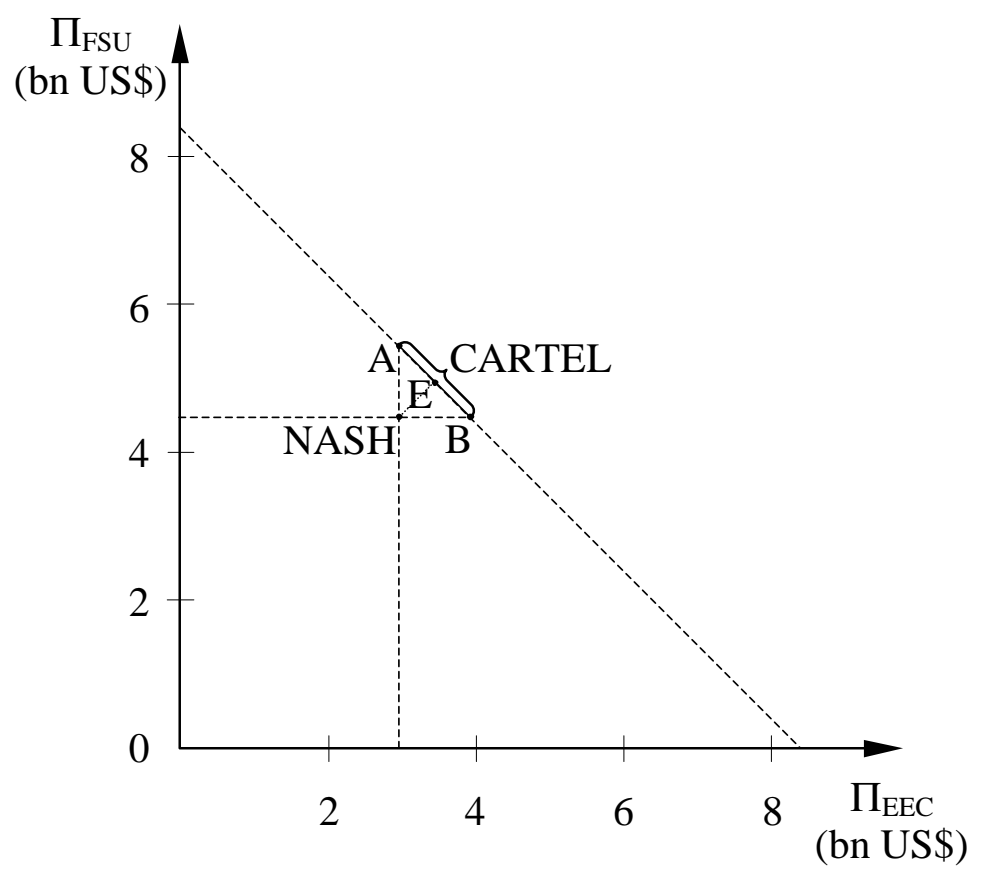

Figure 3 Imputation of monopolistic profits

Under a monopolistic cartel supply, all Kyoto-constrained Annex 1 regions' demand for permits drop from $298 \mathrm{MtC}$ under a perfect competition to $126 \mathrm{MtC}$. This means that 172 $\mathrm{MtC}$ of hot air are suppressed. Annex 1 emissions are reduced from $2.5 \mathrm{GtC}$ to about $2.3 \mathrm{GtC}$, i.e. the environmental effectiveness of the Kyoto protocol is increased by market power on the supply side. Generally speaking, the derived results are expected to be sensitive to the assumptions about the amount of hot air. While this may be particularly the case under the no trade scenario (NOTRADE), the amount of hot air is a far less critical factor under the monopolistic cartel supply examined here, since in this case FSU and EEC supply the complete market with only $126 \mathrm{MtC}$, i.e. about one third of the hot air assumed in the calculations.

The formation of a permit supply cartel does not seem implausible. The cartel has a good ability to raise permit prices since the demand curve is relatively vertical (inelastic). No workable punishment is foreseen to be put in place, since EEC and FSU can otherwise bank their excess hot air permits for subsequent commitment periods as allowed under Article 3.13 of the Kyoto Protocol. The organizational costs are low, in particular due to the regular meetings at the Conference of Parties (COP). But each member of the cartel has an incentive to supply more permits than is best for the cartel collectively. As a result, the cartel tends to 
break apart. Whether this is going to happen depends on the regions' willingness to commit themselves to efficiently coordinated strategies, which in turn boils down to the design of an international emissions trading scheme. This is the greatest challenge ahead for EEC and FSU to reap monopolistic profits from coordinating their permit sales, given that the two regions comprise of a number of countries.

\section{NASH: EEC and FSU as a Cournot duopoly}

The second specification of non-competitive behavior assumes that EEC and FSU act independently of each other, and each region attempts to maximize its profit by choosing its own permit supply. We use a Cournot model of duopoly, where the two regions simultaneously set their quantity supplied to the permits market. Both regions have to consider their rival region's behavior to determine their own optimal choice of permit supply. The maximum profit action by one region, given its beliefs about the action taken by its rival, is represented by the best-response (or reaction) function. A Nash equilibrium corresponds with an intersection of the two best-response functions. In the Nash equilibrium, no player has an incentive to deviate from his prescribed strategy. Each region sells the quantity of permits that maximizes its profits given its (correct) beliefs about other regions' choice of permit supply. Reaction curves are drawn in Figure 4. The best response function of FSU $\left(\mathrm{BR}_{\mathrm{FSU}}\right)$ has two significant points: if EEC supplies zero permits, FSU provides $126 \mathrm{MtC}$. This is the cartel (monopoly) output level, since a Cournot player without competition faces the market demand curve. If EEC supplies $298 \mathrm{MtC}$, the total emission reduction required of the Kyotoconstrained Annex 1 regions, FSU provides zero permits. However, the two regions are not identical. FSU has hot air of $296 \mathrm{MtC}$ and will not be engaged in any abatement activities. $\mathrm{EEC}$, on the other hand, has hot air of only $56 \mathrm{MtC}$. The permit exports beyond the amount of hot air are generated by undertaking domestic abatement efforts to earn additional profits. EEC abates domestically up to the point where the marginal abatement cost of generating one additional permit equals its marginal revenue. This is the reason why the best response function of EEC $\left(\mathrm{BR}_{\mathrm{EEC}}\right)$ is kinked: the best response function is symmetric to the one of FSU if only hot air is supplied, but differs in the case of domestic abatement efforts by EEC. If FSU supplies zero permits, EEC provides only $87 \mathrm{MtC}$, i.e. hot air of $56 \mathrm{MtC}$ and an additional $31 \mathrm{MtC}$ resulting from domestic abatement action. Again, if FSU supplies 298 $\mathrm{MtC}, \mathrm{EEC}$ offers zero permits. In the Nash equilibrium, FSU exports permits of $96 \mathrm{MtC}$ and 
EEC permits of $70 \mathrm{MtC}$. The total market supply of permits amounts to $166 \mathrm{MtC}$, and the corresponding price of permits equals $46 \mathrm{US} \$ / \mathrm{tC}$. In comparison with the scenario CARTEL, the market supply of permits under the Nash competition is increased by $40 \mathrm{MtC}$ and the price of permits is reduced by $20 \mathrm{US} \$ / \mathrm{tC}$. The profits are US\$ 4.4 bn for FSU and US\$ 3.1 bn for EEC in the Nash equilibrium. The costs of meeting the revised Kyoto targets are US\$ 1.0 bn for AUN, US\$ 1.2 bn for CAN, US\$ 5.6 bn for EUR and US\$ 2.3 bn for JPN. Summing over these costs minus the profits of FSU and EEC leads to the total remaining Annex 1 compliance cost of US\$ 2.6 bn. In comparison with that of US\$ 4.8 bn under CARTEL, this total compliance cost under NASH is almost cut in half.

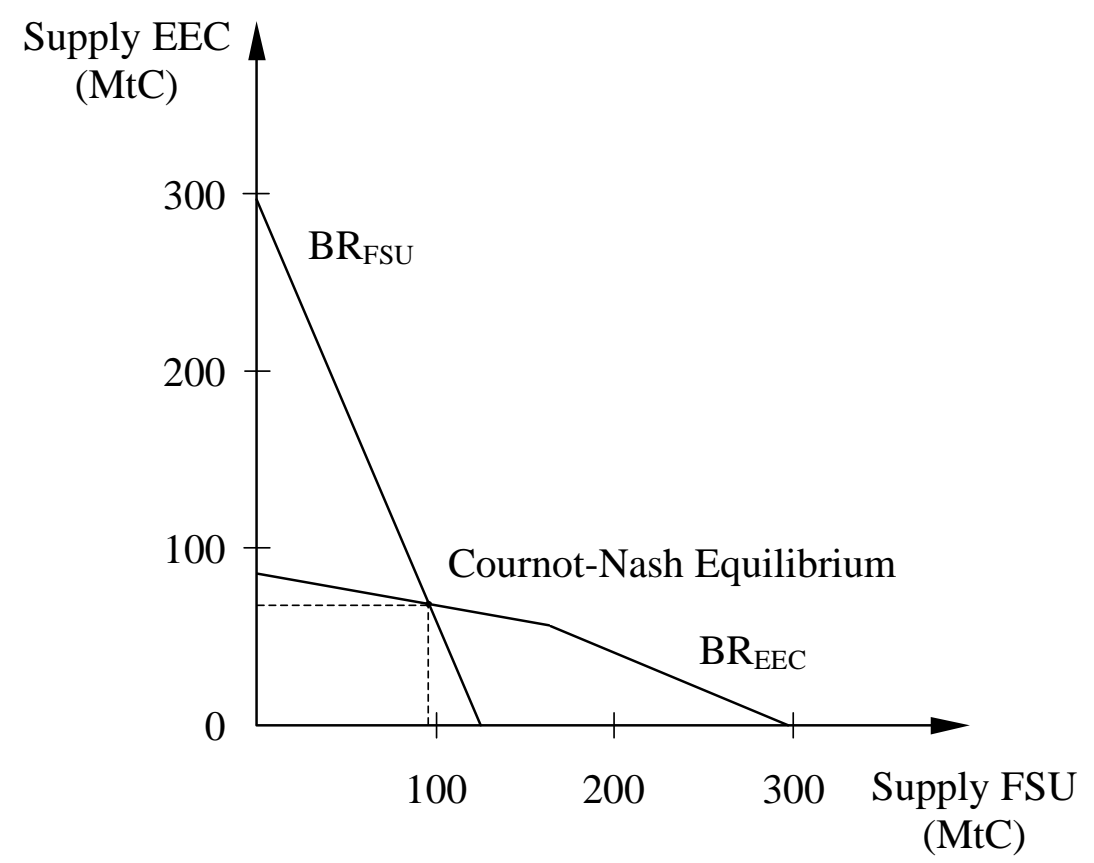

Figure 4 EEC and FSU as a Cournot duopoly

\section{E. MONOP - Only FSU exercises monopoly power}

Under the last imperfect competition scenario, only FSU is assumed to exercise market power, while EEC is assumed to be a price taker on the permit market. This assumption seems realistic given the dominant position of Russia and the Ukraine on the supply side of the international emissions trading market. The small supplier EEC is then treated as a competitive fringe and follows the price leadership of the dominant region FSU. In this case, FSU knows how much EEC supplies at any given price and adjusts the residual demand curve accordingly. Acting as a monopoly, FSU supplies $102 \mathrm{MtC}$ at a price of 36 
US\$/tC. The maximum monopolistic profit of FSU is reduced to US\$ 3.6 bn from 4.4 bn US\$ under NASH and 4.8 bn US\$ under CARTEL. The fringe supplier EEC delivers $86 \mathrm{MtC}$ to the market and gets a profit of US\$ 2.6 bn (US\$ 3.1 bn revenues from sales less US\$ 0.5 bn costs of abatement) in comparison with US\$ 3.1 bn under NASH and US\$ 3.5 bn under CARTEL. The total volume of permits traded between the hot air suppliers and the other Annex 1 regions increases to $188 \mathrm{MtC}$ from $126 \mathrm{MtC}$ under CARTEL and $166 \mathrm{MtC}$ under NASH. The total costs of all remaining Kyoto-constrained Annex 1 regions meeting the Kyoto abatement requirements are reduced to US\$ 8.4 bn: US\$ 0.9 bn for AUN, US\$ 1.0 bn for CAN, US\$ 4.6 bn for EUR and US\$ 1.9 bn for JPN.

Table 3 summarizes the results of the different policy simulations undertaken, and Figure 5 illustrates these quantitative results. Our results show that there is ample space for non-competitive supply behavior under Annex 1 emissions trading. Without the US participation, the residual demand of all remaining Kyoto-constrained Annex 1 regions is given by the curve D. Under competitive Annex 1 emissions trading TRD/US, FSU and EEC supply hot air in excess of market demand. If FSU and EEC together exercise monopoly power (CARTEL), they sell hot air permits until the marginal revenues of permit sales (MR) are equal to the marginal costs of abatement, which are zero. If only FSU exercises monopoly power and EEC is treated as a fringe supplier (MONOP), FSU perceives the permit demand curve $\mathrm{D}_{/ \mathrm{EEC}}$. FSU sells hot air until the marginal revenues of permit sales $\left(\mathrm{MR}_{/ \mathrm{EEC}}\right)$ equal zero. As indicated in Figure 5, the market equilibrium under Nash lies just between the CARTEL and the MONOP solutions on the market demand curve D. Clearly, the supply restrictions imposed as a result of different degree of monopoly power on the permit market all result in, to some extent, an increase in the international permit price and real emission reduction. With the US participation, the residual demand curve faced by the suppliers FSU and EEC with supply curve $S$ is depicted by the curve $D_{\text {US. In }}$ this case, the competitive permit market equilibrium is given by $\mathrm{TRD}_{\mathrm{US}}$. 
Table 3 Implications of the non-competitive supply behavior for the permits market, compliance costs and the environmental effectiveness in 2010

\begin{tabular}{|c|c|c|c|c|c|c|}
\hline & NTR & TRD w/o US & TRD w/t US & CARTEL & NASH & MONOP \\
\hline \multicolumn{7}{|c|}{ Absolute cost of compliance (bn US\$) } \\
\hline AUN & 1.5 & 0 & 1.0 & 1.3 & 1.0 & 0.9 \\
\hline CAN & 2.6 & 0 & 1.1 & 1.6 & 1.2 & 1.0 \\
\hline EEC & 0 & 0 & -3.1 & $-3.5^{f}$ & -3.1 & -2.6 \\
\hline EUR & 9.0 & 0 & 5.1 & 7.1 & 5.6 & 4.6 \\
\hline FSU & 0 & 0 & -14.4 & $-4.8^{\mathrm{f}}$ & -4.4 & -3.6 \\
\hline JPN & 5.1 & 0 & 2.1 & 3.1 & 2.3 & 1.9 \\
\hline Total w/o US & 18.2 & 0 & - & 4.8 & 2.6 & 2.1 \\
\hline USA & 31.3 & - & 15.9 & - & - & - \\
\hline Total w/t US & 49.5 & - & 7.7 & - & - & - \\
\hline \multicolumn{7}{|c|}{ Relative cost of compliance (\% of business-as-usual GDP in 2010) } \\
\hline AUN & 0.22 & 0 & 0.14 & 0.19 & 0.15 & 0.13 \\
\hline CAN & 0.27 & 0 & 0.12 & 0.16 & 0.12 & 0.10 \\
\hline EEC & 0 & 0 & -0.51 & $-0.57^{f}$ & -0.52 & -0.44 \\
\hline EUR & 0.08 & 0 & 0.04 & 0.06 & 0.05 & 0.04 \\
\hline FSU & 0 & 0 & -1.66 & $-0.55^{f}$ & -0.51 & -0.42 \\
\hline JPN & 0.11 & 0 & 0.04 & 0.07 & 0.05 & 0.04 \\
\hline Total w/o US & 0.09 & 0 & - & 0.02 & 0.01 & 0.01 \\
\hline USA & 0.24 & - & 0.12 & - & - & - \\
\hline Total w/t US a & 0.15 & - & 0.02 & - & - & - \\
\hline \multicolumn{7}{|c|}{ Absolute real emission reduction (MtC) } \\
\hline AUN & 33.7 & 0 & 17.2 & 24.0 & 18.6 & 15.6 \\
\hline CAN & 32.5 & 0 & 10.6 & 15.1 & 11.5 & 9.6 \\
\hline EEC & 0 & 0 & 33.1 & 0 & 13.7 & 30.1 \\
\hline EUR & 167.9 & 0 & 73.2 & 104.1 & 79.6 & 66.4 \\
\hline FSU & 0 & 0 & 97.3 & 0 & 0 & 0 \\
\hline JPN & 64.0 & 0 & 20.4 & 29.3 & 22.3 & 18.5 \\
\hline Total w/o US & 298.0 & 0 & - & 172.4 & 145.6 & 140.2 \\
\hline USA & 513.8 & - & 208.1 & - & - & - \\
\hline Total w/t US & 811.8 & - & 459.9 & - & - & - \\
\hline
\end{tabular}


Table 3 continued.

\begin{tabular}{|c|c|c|c|c|c|c|}
\hline & NTR & \multicolumn{2}{|c|}{ TRD w/o US TRD w/t US } & CARTEL & NASH & MONOP \\
\hline \multicolumn{7}{|c|}{ Relative real emission reduction (\% from business-as-usual in 2010) } \\
\hline AUN & 25.9 & 0 & 13.2 & 18.4 & 14.3 & 12.0 \\
\hline CAN & 19.7 & 0 & 6.4 & 9.1 & 7.0 & 5.8 \\
\hline EEC & 0 & 0 & 15.8 & 0 & 6.6 & 14.4 \\
\hline EUR & 16.1 & 0 & 7.0 & 10.0 & 7.7 & 6.4 \\
\hline FSU & 0 & 0 & 16.4 & 0 & 0 & 0 \\
\hline JPN & 19.3 & 0 & 6.2 & 8.8 & 6.7 & 5.6 \\
\hline Total w/o US & 7.0 & 0 & - & 4.0 & 3.4 & 3.3 \\
\hline USA & 28.4 & - & 11.5 & - & - & - \\
\hline Total w/t US ${ }^{b}$ & 19.0 & - & 10.8 & - & - & - \\
\hline \multicolumn{7}{|c|}{ Amount of hot air emitted into the atmosphere (MtC) } \\
\hline Total w/o US & 0 & 298.0 & - & 125.6 & 152.4 & 157.8 \\
\hline Total w/t US & 0 & - & 351.9 & - & - & - \\
\hline \multicolumn{7}{|c|}{ Market price (US $\$ / \mathrm{tC}$ ) } \\
\hline & $-^{\mathrm{c}}$ & 0 & 40.7 & 65.9 & 45.6 & 35.6 \\
\hline \multicolumn{7}{|c|}{ Market size (MtC) } \\
\hline & $-{ }^{c}$ & 298.0 & 482.2 & 125.6 & 166.0 & 188.1 \\
\hline \multicolumn{7}{|c|}{ Permit trade $(\mathrm{MtC})^{\mathrm{d}}$} \\
\hline AUN & - & 33.7 & 16.6 & 9.7 & 15.1 & 18.1 \\
\hline CAN & - & 32.5 & 21.8 & 17.4 & 20.9 & 22.8 \\
\hline EEC & - &. $\mathrm{e}$ & -89.4 & . e & -70.0 & -86.4 \\
\hline EUR & - & 167.9 & 94.7 & 63.8 & 88.3 & 101.5 \\
\hline FSU & - &. $\mathrm{e}$ & -392.8 & . e & -96.0 & -101.8 \\
\hline JPN & - & 64.0 & 43.5 & 34.7 & 41.7 & 45.5 \\
\hline USA & - & - & 305.6 & - & - & - \\
\hline
\end{tabular}

a Percentage change with respect to aggregate Annex 1 business-as-usual GDP in 2010.

b Percentage change with respect to total Annex 1 baseline emissions in 2010 including the US emissions.

c Autarkic marginal abatement costs are $108 \mathrm{US} \$ / \mathrm{tC}$ for AUN, $190 \mathrm{US} \$ / \mathrm{tC}$ for CAN, $127 \mathrm{US} \$ / \mathrm{tC}$ for EUR, 187 US $\$ / t C$ for JPN and 148 US\$/tC for USA.

${ }^{\mathrm{d}}$ Positive values indicate permit imports, negative values indicate permit exports.

e Permit exports by EEC and FSU are undetermined. Under TRD w/o US total permit supply is 298 MTC, while the corresponding figure under CARTEL equals $126 \mathrm{MtC}$.

${ }^{\mathrm{f}}$ If cartel profits are split up following the egalitarian solution. 


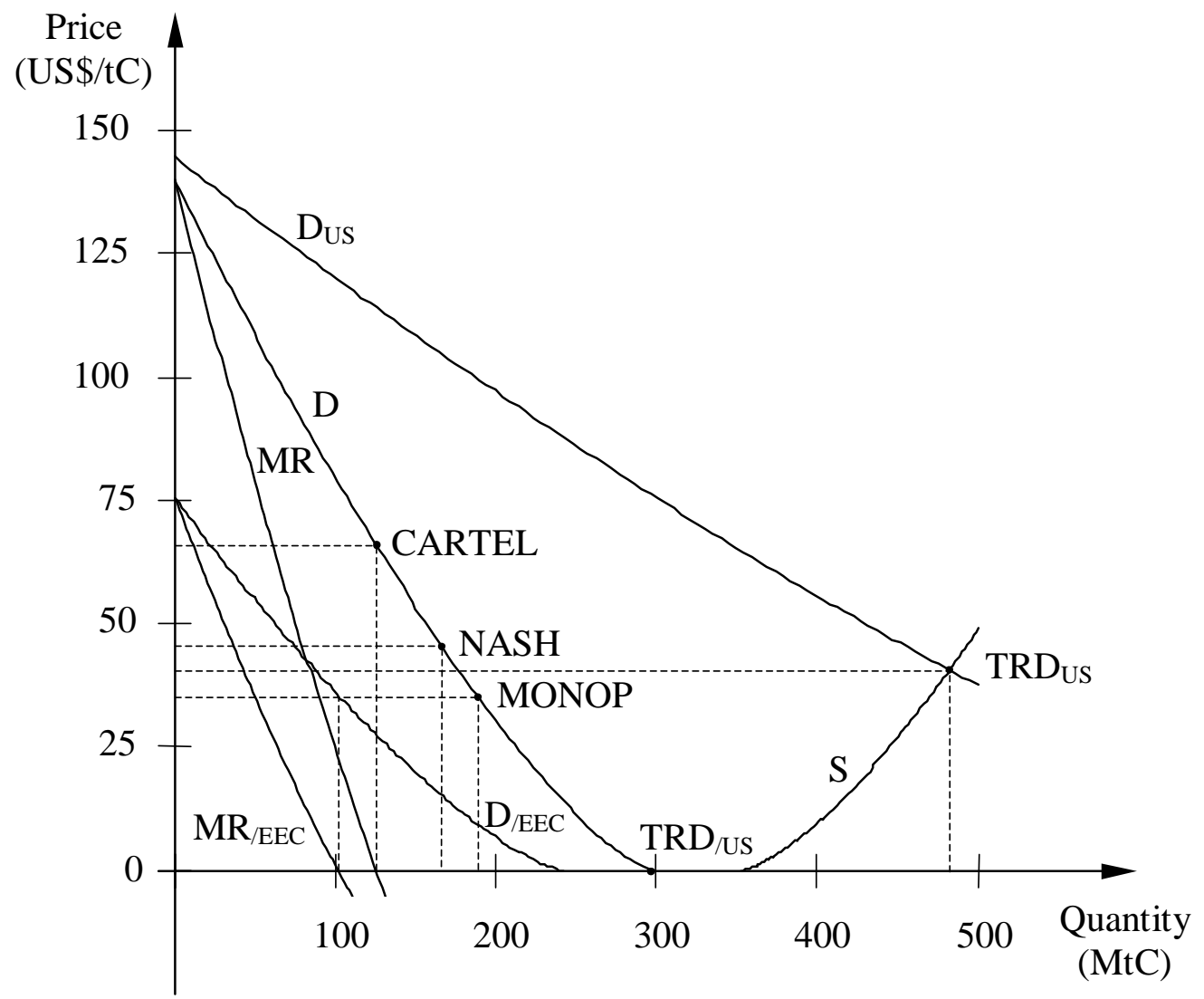

Figure 5 Graphical illustration of the results

\section{Conclusions and further research}

The US withdrawal from the Kyoto Protocol topples the balance of the buyers and sellers on the international market of tradable permits. With the over-supply of permits, it seems likely that sellers would adapt their behavior to the weaker demand for emissions permits to maximize their gains. Taking account of sinks credits as agreed in Bonn and Marrakech, this paper has illustrated how market power could be exerted in the absence of the US ratification under Annex 1 trading and has explored the potential implications of the noncompetitive supply behavior for the international market of tradable permits, compliance costs for the remaining Annex 1 countries to meet their revised Kyoto targets, and the environmental effectiveness.

As the largest carbon emitter in the world, the US withdrawal from the Kyoto Protocol has had by far the greatest impact on the environmental effectiveness of the Protocol. This 
would lead to no real emission reduction in any of the remaining Annex 1 regions, whereas the ratification of all Annex 1 regions, including the US, would result in the real emission reduction of $812 \mathrm{MtC}$ or $19.0 \%$ below the total Annex 1 baseline emissions in 2010 (if trading across Annex 1 countries were not allowed) and of $460 \mathrm{MtC}$ or $10.8 \%$ below the total Annex 1 baseline emissions in 2010 (if trading across Annex 1 countries were allowed). As the biggest single buyer on the international market of tradable permits, the absence of the US ratification would significantly reduce the demand for permits. As a consequence, the price of permits under Annex 1 trading would drop from US\$ 40.7 per ton of carbon with US ratification to zero without the US ratification. All remaining Kyoto-constrained Annex 1 countries could benefit from the excess supply of hot air from FSU and EEC and meet their Kyoto targets at zero costs. But seller countries would lose all their revenues under perfect Annex 1 trading.

Given FSU and EEC as the dominant suppliers of emissions permits on the international market, it is certainly not in their interest to sell excess emissions permits at zero price. Instead, they may exert market power to maximize their revenues from selling permits. Our results show that such supply restrictions by exploiting market power results in substantial economic losses for all remaining Kyoto-constrained Annex 1 regions in comparison with the case of perfectly competitive supply, while it generates substantial financial flows to FSU. Depending on how market power is exerted under Annex 1 trading, the overall compliance costs of all remaining Annex 1 regions in the case where FSU and EEC form a sellers' cartel (CARTEL) could reach as much as two times that in the case where only FSU acts as a monopoly (MONOP). But no matter how market power is exerted under Annex 1 trading, all Kyoto-constrained Annex 1 regions are better off with emissions trading in terms of their compliance costs than with no trading at all. Moreover, curtailing permit supply by market power will cut the amount of hot air being emitted into the atmosphere by more than half and at the same time, increases Annex 1 domestic abatement efforts. Thus, the overall environmental effectiveness is increased in comparison with the case of perfectly competitive supply, although real emissions reductions are much less effective under the market power scenarios examined here than in the case of the ratification of all Annex 1 regions including the US.

There are several aspects that warrant further investigation. First, our analysis focuses on the first commitment period, and does not consider the possibility of banking of permits. It 
is conceivable that a low price in the first commitment period will induce sellers to defer portion of their emissions permits for use in subsequent periods (Manne and Richels, 2001). Such flexibility is particularly attractive if sellers expect much higher prices of permits in the subsequent periods due to a further tightening of emissions targets, reentry of the US to the Kyoto Protocol, and/or higher compliance costs encountered by themselves as their economies are expected to begin recovering in the subsequent commitment periods. Second, our analysis is based on a partial equilibrium framework, ignoring other potential effects of non-competitive supply behavior, notably the potential negative terms-of-trade consequences. ${ }^{11}$ Thus, it would be interesting to identify the sources of the differences between the partial equilibrium results and the respective general equilibrium results, and to quantify their significance.

It should be pointed out that our analysis only examines the issue of market power on the supply side under Annex 1 trading. Some analysts (e.g., Böhringer and Löschel, 2001) suggest considering the possibility of expanding emissions trading to include developing countries via CDM to diminish FSU and EEC's ability to exercise market power. Incorporating developing countries into an international emissions trading scheme not only increases the number of market participants, but also makes more cheap permits available. Both effects reduce FSU and EEC's ability to exert market power. But the point is that the US withdrawal leaves plenty of excess hot air of zero costs. This will substantially reduce incentives to invest in $\mathrm{CDM}$ projects that imply reduced financial flows channeled to developing countries through CDM. Thus, developing countries might not oppose such a supply side cartelization so that they can benefit from the corresponding high price of permits. After all, their certified emission reductions from CDM projects, although less costly than the equivalent amount of abatement undertaken within Annex 1 purchasing countries, are not made available at zero costs. Some OECD countries, particularly those more concerned about the environmental effectiveness of the Kyoto Protocol, would also not necessarily interfere with such a move, as it would compel the remaining Kyoto-constrained Annex 1 countries to

\footnotetext{
${ }^{11}$ For example, monopolistic pricing on the international permits market influences the prices and quantities of other goods traded internationally. Such effects are transmitted through the trade channels to other trading partners. The resulting feedback effects on the monopolist, for example Russia, who is dependent heavily on oil and gas exports, are that it could lose in relative terms from setting higher permit prices through its negative impact on international oil and gas prices. Based on general equilibrium models, earlier studies on compliance with the original Kyoto emissions targets (e.g., Bernstein et al., 1999; Burniaux, 1998; MacCracken et al., 1999) have assessed such potential effects of market power.
} 
undertake otherwise very little domestic abatement actions and at the same time, would still reduce their costs of compliance. 


\section{References}

Buchner, B., Carraro, C. and I. Cersosimo (2001), On the Consequences of the U.S. Withdrawal from the Kyoto/Bonn Protocol, FEEM Working Paper 102.01, Fondazione Eni Enrico Mattei (FEEM), Milano, Italy.

Bernstein, P., Montgomery, D., Rutherford, T.F. and G. Yang (1999), Effects of Restrictions on International Permit Trading: The MS-MRT Model, The Energy Journal, Vol. 20 (Special Issue), pp. 221-257.

Böhringer, C. and A. Löschel (2001), Market Power in International Emission Trading: The Impacts of U.S. Withdrawal from the Kyoto Protocol, Discussion Paper No. 01-58, Centre for European Economic Research, Mannheim, Germany.

Bollen, J., Gielen, A. and H. Timmer (1999), Clubs, Ceilings and CDM - Macroeconomics of Compliance with the Kyoto Protocol, The Energy Journal, Vol. 20 (Special Issue), pp. 177-206.

Burniaux, J.-M. (1998), How Important Is Market Power in Achieving Kyoto?: An Assessment Based on the GREEN Model, in OECD (ed.), Economic Modelling of Climate Change, Paris.

Commission of European Communities (2001), Proposal for a Directive of the European Parliament and of the Council Establishing a Framework for Greenhouse Gas Emissions Trading within the European Community and Amending Council Directive 96/61/EC, $\operatorname{COM}(2001) 581$, Brussels, 23 October.

Cramton, P. and S. Kerr (1998), Tradeable Carbon Allowance Auctions: How and Why to Auction, mimeo, University of Maryland at College Park.

Criqui, P. and L. Viguier (2000), Trading Rules for $\mathrm{CO}_{2}$ Emission Permits Systems: A Proposal for Ceilings on Quantities and Prices, IEPE Cahier de Recherche 18 bis, Institute of Energy Policy and Economics, Grenoble, France.

Criqui, P., Mima, S. and L. Viguier (1999), Marginal Abatement Costs of $\mathrm{CO}_{2}$ Emission Reductions, Geographical Flexibility and Concrete Ceilings: An Assessment Using the POLES Model, Energy Policy, Vol. 27, No. 10, pp. 585-602.

Criqui, P., Cattier, F., Menanteau, P. and M.-C. Quidoz (1996), POLES 2.2. Reference Guide, Institute of Energy Policy and Economics, Grenoble, France. 
Den Elzen, M.G.J. and A.P.G. de Moor (2001), Evaluating the Bonn Agreement and Some Key Issues, RIVM Report 728001016, RIVM, Bilthoven, The Netherlands.

DOE (2001), International Energy Outlook, Energy Information Administration, US Department of Energy (DOE), Washington, DC.

Ellerman, A.D. and A. Decaux (1998), Analysis of Post-Kyoto $\mathrm{CO}_{2}$ Emissions Trading Using Marginal Abatement Curves, MIT Joint Program on the Science and Policy of Global Change, Report No. 40, Massachusetts Institute of Technology.

Ellerman, A.D. and I. S. Wing (2000), Supplemantarity: An Invitation for Monopsony, The Energy Journal, Vol. 21, No. 4, pp. 29-59.

Ellerman, A.D., Jacoby, H.D. and A. Decaux (1998), The Effects on Developing Countries of the Kyoto Protocol and $\mathrm{CO}_{2}$ Emissions Trading, MIT Joint Program on the Science and Policy of Global Change, Report No. 41, Massachusetts Institute of Technology.

European Union (1999), Community Strategy on Climate Change: Council Conclusions, No. 8346/99, 18 May, Brussels.

Eyckmans, J., Van Regemorter, D. and V. van Steenberghe (2001), Is Kyoto fatally flawed? An analysis with MacGEM, Energy, Transport and Environment Working Paper Series No. 2001-18, Center For Economic Studies, Katholieke University Leuven, Leuven Belgium.

Godby, R. (2000), Market Power and Emissions Trading: Theory and Laboratory Results, Pacific Economics Review, Vol. 5, No. 3, pp. 349-363.

Hagem, C. and B. Holtsmark (2001), From Small to Insignificant: Climate Impact of the Kyoto Protocol with and without US, CICERO Policy Note No. 1, Center for International Climate and Environmental Research (CICERO), Oslo.

Hahn, R.W. (1984), Market Power in Transferable Property Rights, Quarterly Journal of Economics, Vol. 99, No. 4, pp. 753-765.

Hargrave, T. (1998), US Carbon Emissions Trading: Description of an Upstream Approach, Center for Clear Air Policy, Washington, DC.

IISD (2001), Summary of the Seventh Conference of the Parties to the UN Framework Convention on Climate Change: 29 October - 10 November 2001, Earth Negotiation Bulletin, Vol. 12, No. 189, International Institute of Sustainable Development (IISD), Winnipeg, Canada. 
Legge, T. (2001), The Unexpected Triumph of Optimism over Experience, CEPS Commentary, Center for European Policy Studies (CEPS), Brussels.

MacCracken, C., Edmonds, J., Kim, S. and R. Sands (1999), The Economics of the Kyoto Protocol, The Energy Journal, Vol. 20 (Special Issue), pp. 25-71.

Malueg, D.A. (1990), Welfare Consequences of Emission Credit Trading Programs, Journal of Environmental Economics and Management, Vol. 18, pp. 66-77.

Manne, A. and R. Richels (1999), The Kyoto Protocol: A Cost-effective Strategy for Meeting Environmental Objectives?, The Energy Journal, Vol. 20 (Special Issue), pp. 1-23.

Manne, A. and R. Richels (2001), US Rejection of the Kyoto Protocol: The Impact on Compliance Costs and $\mathrm{CO}_{2}$ Emissions, Presented at the Stanford Energy Modeling Forum Meeting on Burden Sharing and the Costs of Mitigation, Snowmass, Colorado, August 6.

Misiolek, W. S. and H. W. Elder (1989), Exclusionary Manipulation of Markets for Pollution Rights, Journal of Environmental Economics and Management, Vol. 16, No. 2, pp. 156166.

Nemry, F. (2001), LULUCF39 v4 - Quantitative implications of the decision -/CP.7 on LULUCF, Personal Communication.

Paltsev, S. V. (2000), The Kyoto Protocol: "Hot Air" for Russia?, Working Paper 00-9, Department of Economics, University of Colorado, Boulder.

Sartzetakis, E. S. (1997), Tradeable Emission Permits Regulations in the Presence of Imperfectly Competitive Product Markets: Welfare Implications, Environmental and Resource Economics, Vol. 9, No. 1, pp. 65-81.

UNFCCC (1997), Kyoto Protocol to the United Nations Framework Convention on Climate Change (UNFCCC), FCCC/CP/1997/L.7/Add.1, Bonn.

UNFCCC (2001), Review of the Implementation of Commitments and of other Provisions of the Convention. Preparations for the First Session of the Conference of the Parties Serving as the Meeting of the Parties to the Kyoto Protocol (Decision 8/CP.4): Decision 5/CP.6, Implementation of the Buenos Aires Plan of Action, United Nations Framework Convention on Climate Change (UNFCCC), FCCC/CP/2001/L.7, Bonn.

Westkog, H. (1996), Market Power in a System of Tradeable $\mathrm{CO}_{2}$-Quotas, Energy Journal, Vol. 17, No. 3, pp. 85-103. 
Weyant, J.P. (ed., 1999), The Cost of the Kyoto Protocol: A Multi-Model Evaluation, Energy Journal, Vol. 20 (Special Issue), pp. 1-398.

Zhang, Z.X. (1998), Greenhouse Gas Emissions Trading and the World Trading Systems, Journal of World Trade, Vol. 32, No. 5, pp. 219-239.

Zhang, Z.X. (2000a), The Design and Implementation of an International Greenhouse Gas Emissions Trading Scheme, Environment and Planning C: Government and Policy, Vol. 18, No. 3, pp. 321-337.

Zhang, Z.X. (2000b), Estimating the Size of the Potential Market for the Kyoto Flexibility Mechanisms, Weltwirtschaftliches Archiv - Review of World Economics, Vol. 136, No. 3, pp. 491-521.

Zhang, Z.X. (2001), An Assessment of the EU Proposal for Ceilings on the Use of Kyoto Flexibility Mechanisms, Ecological Economics, Vol. 37, No. 1, pp. 53-69. 
Appendix A: The original Kyoto GHG emission reduction targets and the revised targets under the Bonn Agreement and the Marrakech Accords

\begin{tabular}{|c|c|c|c|c|}
\hline & Label $^{\mathrm{a}}$ & Target w/o sinks & Sinks credits ${ }^{c}$ & Targets w/t sinks \\
\hline Australia & AUN & 108 & 2.7 & 110.7 \\
\hline Austria & EUR & 87 & 4.0 & 91 \\
\hline Belgium & EUR & 92.5 & 1.1 & 93.6 \\
\hline Bulgaria & EEC & 92 & 2.1 & 94.1 \\
\hline Canada & $\mathrm{CAN}$ & 94 & 11.2 & 105.2 \\
\hline Czech Republic & EEC & 92 & 1.6 & 93.6 \\
\hline Denmark & EUR & 79 & 1.2 & 80.2 \\
\hline Estonia & EEC & 92 & 1.9 & 93.9 \\
\hline Finland & EUR & 100 & 1.8 & 101.8 \\
\hline France & EUR & 100 & 1.6 & 101.6 \\
\hline Germany & EUR & 79 & 1.4 & 80.4 \\
\hline Greece & EUR & 125 & 1.3 & 126.3 \\
\hline Hungary & $\mathrm{EEC}$ & 94 & 2.2 & 96.2 \\
\hline Iceland & EUR & 110 & 8.0 & 118 \\
\hline Ireland & EUR & 113 & 1.4 & 114.4 \\
\hline Italy & EUR & 93.5 & 1.1 & 94.6 \\
\hline Japan & JPN & 94 & 4.9 & 98.9 \\
\hline Latvia & EEC & 92 & 2.9 & 94.9 \\
\hline Liechtenstein & EUR & 92 & 15.1 & 107.1 \\
\hline Lithuania & EEC & 92 & 3.0 & 95 \\
\hline Luxembourg & EUR & 72 & 1.4 & 79.4 \\
\hline Monaco & EUR & 92 & 1.0 & 93 \\
\hline Netherlands & EUR & 94 & 1.0 & 95 \\
\hline New Zealand & AUN & 100 & 2.0 & 102 \\
\hline Norway & EUR & 101 & 3.8 & 104.8 \\
\hline Poland & $\mathrm{EEC}$ & 94 & 1.7 & 95.7 \\
\hline Portugal & EUR & 127 & 2.2 & 129.2 \\
\hline Romania & $\mathrm{EEC}$ & 92 & 2.8 & 94.8 \\
\hline Russian Federation & FSU & 100 & 5.0 & 105 \\
\hline Slovakia & EEC & 92 & 3.5 & 95.5 \\
\hline Slovenia & EEC & 92 & 7.9 & 99.9 \\
\hline Spain & EUR & 115 & 1.8 & 116.8 \\
\hline Sweden & EUR & 104 & 4.0 & 108 \\
\hline Switzerland & EUR & 92 & 4.5 & 96.5 \\
\hline Ukraine & FSU & 100 & 1.4 & 101.4 \\
\hline United Kingdom & EUR & 87.5 & 1.3 & 88.8 \\
\hline United States & USA & 93 & 3.3 & 96.3 \\
\hline
\end{tabular}

a Label used to correspond to those Annex 1 countries covered in each aggregate region modelled.

b As \% of 1990 GHG emissions (UNFCCC, 1997).

c Total allowed sink credits agreed in Bonn and Marrakech as \% of 1990 GHG emissions (Nemry, 2001).

d As \% of 1990 GHG emissions. 


\section{Appendix B: Algebraic model description}

This section provides an algebraic summary of the marginal abatement costs-based, partial equilibrium model for emissions trading underlying the simulations. We begin with the model formulation for a competitive system of emissions trading accounting for hot air, i.e. the scenario TRADE. Then, we lay out the set-up for the case of non-competitive permit supply behavior. The model for the scenarios CARTEL and MONOP is described first. Finally, the model set-up for the scenario NASH is specified.

\section{B.1. Competitive emissions trading with hot air: TRADE}

Under competitive emissions trading, all countries are price takers. Each country $i$ minimizes its compliance costs to some exogenous target level $k_{i}$. Compliance costs equal the sum of abatement costs and the costs of buying carbon permits; in the case of permit sales, the second term becomes negative, which means that the country minimizes the cost of abatement minus the income from selling permits. A country with hot air $\left(h_{i}\right)$ is always selling permits. Costs are minimized subject to the constraint that a country meets its exogenous reduction target. In other words: a country's initial endowment of permits plus the amount of permits bought or sold on the market $\left(q_{i}\right)$ may not exceed the emission target level $k_{i}$ :

$$
\begin{aligned}
& \min _{q_{i}} C_{i}\left(h_{i}+\overline{e_{i}}-e_{i}\right)+P \cdot q_{i} \\
& \text { s.t. } e_{i}=k_{i}+q_{i},
\end{aligned}
$$

where

$C_{i} \quad$ denotes the abatement cost function for reducing carbon emissions,

$\overline{e_{i}} \quad$ stands for the business-as-usual emissions,

$e_{i} \quad$ are the actual emissions, and

$P \quad$ is the permit price taken as exogenous.

The amount of hot air equals the difference between the emission target and the business-asusual emissions:

$$
k_{i}=h_{i}+\overline{e_{i}} .
$$

The first order condition for the cost minimization problem yields: 


$$
C_{i}^{\prime}\left(h_{i}+\overline{e_{i}}-e_{i}\right)=P
$$

In the optimum, the price taking countries abate emissions up to a level where their marginal abatement costs $(C)$ equal the permit price. Total costs of reducing emissions to the overall target level $K=\Sigma k_{i}$ are minimized, since all opportunities for exploiting cost differences in abatement across countries are taken. The existence of hot air does not change the costefficiency property of unrestricted competitive emission trading, since marginal abatement costs are still equalized. However, hot air sold on the permit market does not imply any effective (real) emission reduction in the hot air countries. The occurrence of traded hot air, therefore, results in an increase of overall emission compared to a situation without international emissions trading.

\section{B.2. Non-competitive permit supply behavior}

\section{CARTEL and MONOP}

Monopolistic permit supply is assumed under the scenarios CARTEL and MONOP. It is characterized as a situation in which one region (denoted " $m$ ") has supply power on the permit market while all other countries, denoted as fringe " $f$ ", behave as price takers. The monopoly region under the scenario CARTEL consists of the coordinating regions EEC and FSU, while it is only FSU under the scenario MONOP. In the latter case, EEC is assumed to be part of the fringe. The fringe countries minimize their compliance costs given the permit price set by the monopolist. They emit carbon until the marginal costs of abatement equal the permit price:

$$
C_{f}^{\prime}\left(h_{f}+\overline{e_{f}}-e_{f}\right)=P .
$$

The aggregate permit demand of the fringe, which is in total a net importer of permits, is:

$$
Q_{F}(P)=\sum_{f} q_{f}(P)
$$

The monopolist sets its permit supply $\left(q_{m}<0\right)$ to minimize abatement costs minus income from permit sales:

$$
\begin{aligned}
& \min _{q_{m}} C_{m}\left(h_{m}+\overline{e_{m}}-e_{m}\right)+P \cdot q_{m} \\
& \text { s.t. } \quad e_{m}=k_{m}+q_{m}
\end{aligned}
$$




$$
P=P\left(Q_{F}\right)
$$

where $P$ is the inverse demand function of the fringe countries. The first order condition of the cost minimization problem indicates that the monopolist sets marginal abatement costs equal to marginal revenue:

$$
C_{m}^{\prime}\left(h_{m}+\overline{e_{m}}-e_{m}\right)=P-P^{\prime}\left(Q_{F}\right) \cdot q_{m} .
$$

Comparing Equation 1' with Equation 6, we see that marginal abatement costs are not equalized between the fringe countries and the monopolist, thus resulting in overall efficiency losses due to market power.

\section{NASH}

Under the scenario NASH it is assumed that EEC and FSU set simultaneously their quantity supplied to the permit market given one region' beliefs about the action taken by its rival. Each region, denoted " $n$ ", sets its permit supply $\left(q_{n}\right)$ to minimize abatement costs minus income from permit sales given the choice of permit supply by the other region, denoted "-n":

$$
\begin{array}{cl}
\min _{q_{n}} & C_{n}\left(h_{n}+\overline{e_{n}}-e_{n}\right)+P \cdot q_{n} \\
\text { s.t. } & e_{n}=k_{n}+q_{n} \\
& P=P\left(Q_{F}-\overline{q_{-n}}\right),
\end{array}
$$

where $P$ is the inverse demand function of the fringe countries (Equation 4) taking into account the other region's permit supply $\left(q_{-n}\right)$. The first order condition for the cost minimization problem yields:

$$
C_{n}^{\prime}\left(h_{n}+\overline{e_{n}}-e_{n}\right)=P-P^{\prime}\left(Q_{F}-\overline{q_{-n}}\right) \cdot q_{n},
$$

resulting in the best-response (or reaction) function for the region $n\left(B R_{n}\right)$. The best-response function for the region $-n\left(B R_{-n}\right)$ can be derived accordingly. A Nash equilibrium corresponds to the intersection of the best response functions of EEC and FSU. 